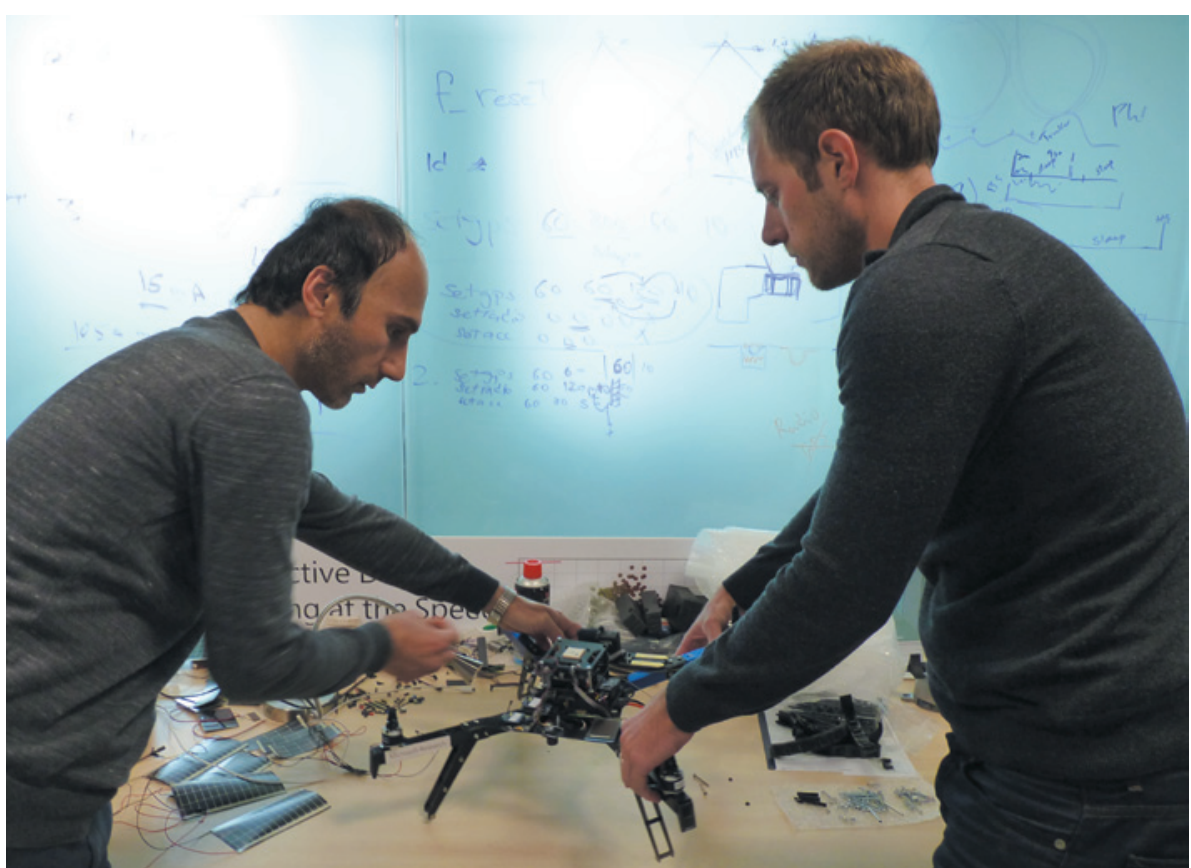

Scientists at Microsoft are at work on a system that uses aerial drones to track wildlife.

\title{
RESEARCH AND DEVELOPMENT
}

\section{Basic science finds} corporate refuge

\section{As many older companies move away from fundamental research, young technology firms are picking up the slack.}

\section{BY NADIA DRAKE}

$\mathrm{M}$ icrosoft makes Windows, Word and the Xbox. But it also employs scientists who make sensors to stick on the hides of elephants and rhinoceroses.

The sensors enable aerial drones to track endangered animals and record changes in their movements that might signify threats, says Lucas Joppa, a conservation biologist at Microsoft's research centre in Cambridge, UK. Joppa uses these massive, complex data sets to inform possible conservation solutions, such as systems that warn responders about poaching. He publishes his research freely. "I get to do world-class science, but I also get to interact with one of the world's most successful businesses," he says.

The ranks of scientists like Joppa are growing, according to economists and observers of trends in science and technology. They suggest that a newer generation of technology-oriented companies - many sitting on mountains of cash after years of growth and
Chayes, managing director of Microsoft's research centres in New York and Cambridge, Massachusetts.

Statistics compiled by the US National Science Foundation (NSF) suggest a jump in industrial funding of basic research beginning in 2006 (see 'Corporate masters'). In a climate of stagnant federal and university funding, the increase stands out. Even as some companies have trimmed their research units, others seem to have bolstered them, says Josh Lerner, an economist at Harvard Business School in Boston, Massachusetts. "For every Pfizer cutting basic research, there has been a Google picking up the slack," he says. The trend, if it solidifies, would signal a reversal from the trajectory of the past several decades, which saw industry support for basic research languish. Many cite the dismantling, from 1996 onwards, of Bell Laboratories in Murray Hill, New Jersey - the iconic industrial research centre that invented the laser, the transistor and radio astronomy - as indicative of this larger malaise.

But tech giants such as Microsoft seem to be leading a corporate-research revival. Spread across the globe, the company's research arm comprises roughly 1,100 scientists in fields as varied as ecology, bioinformatics and the social sciences - as well as the computer scientists and mathematicians one might expect. Researchers there operate with few restrictions on inquiry or publication, although they are expected to produce relevant, insightful work - whether for product development or to advance the understanding of nature.

Companies in California's Silicon Valley are following suit. Google, based in Mountain View, brings dozens of outside scientists to its offices for as many as 18 months at a time and spends more than US\$30 million annually on grants and fellowships. On 17 April, Twitter, in San Francisco, announced the winners of a programme to let scientists answer research questions using Twitter data. And in December, Facebook, in Menlo Park, tapped Yann LeCun, a computer scientist at New York University, to lead its new artificial-intelligence research group. "There was of a bit of a period until recently where there were very few places in industry where you could do real research," says LeCun.

Another hint at the changing landscape comes from an analysis of company-published research papers. Since 1996, the number of papers associated with older, manufacturingoriented companies has plummeted, while publications involving younger technology and Internet companies have increased (see 'New kids on the block'). Lerner says the trend is "a changing of the guard".

Still, some observers question whether the jump in funding for basic research is real. The NSF numbers, for example, rely on a survey sent to roughly 40,000 companies that are selected each year from a pool of nearly 


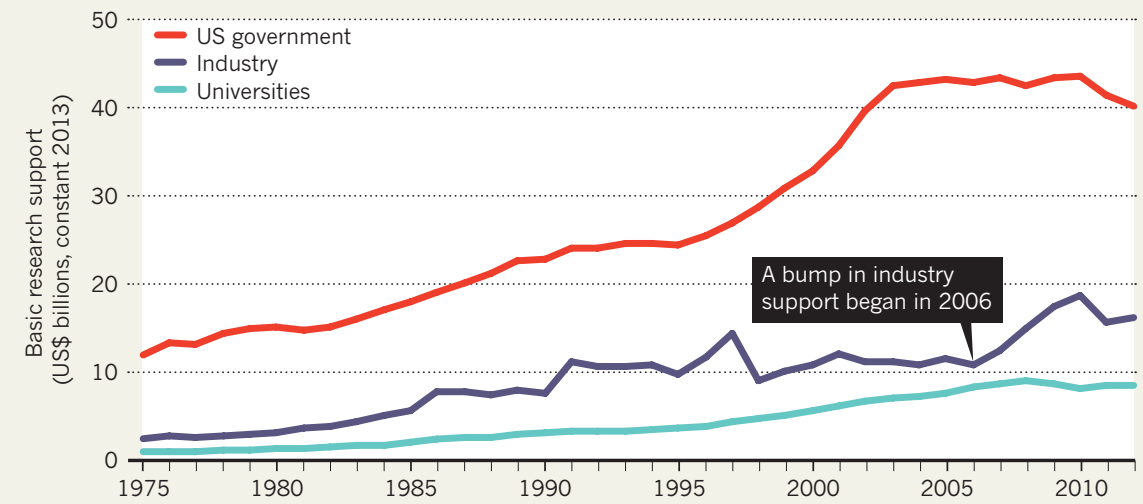

2 million. Because the respondents are kept anonymous, it is impossible to know which companies are included in a given year. Companies also self-report how much they invest in basic and applied research - so the upswing in funding could have as much to do with how companies define basic research as anything else, says Matt Hourihan, director of the research and development budget and policy programme at the American Association for the Advancement of Science in Washington DC. "But," he adds, "it could be a reflection of reality."

\section{BACK TO BASICS}

The terms 'basic' and 'applied' hark back to Vannevar Bush, a scientist who served as head of the US Office of Scientific Research and Development during the Second World War. "Basic research is performed without thought of practical ends," Bush wrote in Science, the Endless Frontier, his 1945 report for the US government. That definition is still pervasive, but companies take slightly different views on how to define and classify projects Joppa's wildlife-sensor project, for example, fits Microsoft's definition of basic research even though it informs an application (albeit one Microsoft has not historically been interested in). "It's multidisciplinary, disruptive, blue-sky research at its finest," says Chayes.

Some companies, such as Intel, in Santa Clara, California, are explicit about focusing on applied research. At Google, by contrast, scientists are encouraged to pursue "use-inspired basic research", says Alfred Spector, vice-president of research at the company. That means employees often pursue fundamental inquiries that are related to Google's business goals, such as the neuroscience of language-learning or speech perception.

Scientists point to IBM's research lab in Zurich, Switzerland, as an exemplar of innovation through company-funded basic research. A fundamental curiosity about what surfaces look like on an atomic scale led to the 1981 invention of the scanning tunnelling microscope, which in turn helped to usher in the field of nanoscience. From there, the IBM team moved on to build the atomic force microscope, which can image the bonds between single atoms.

Although the Zurich lab is small, four of its members have earned Nobel prizes, and the lab boasts a handful of highly competitive European Research Council grants. Scientists there address basic research questions in physics and biology, as well as slightly more applied topics, such as quantum cryptography, big data and cloud computing. The applied research can sometimes lead back to basic questions, says lab director Matthias Kaiserswerth.

"Basic research, as far as we are concerned, is something where we really want to advance the knowledge of mankind," he says. "What we find is that even if we do applied research, there's always some fundamental question we want to answer."

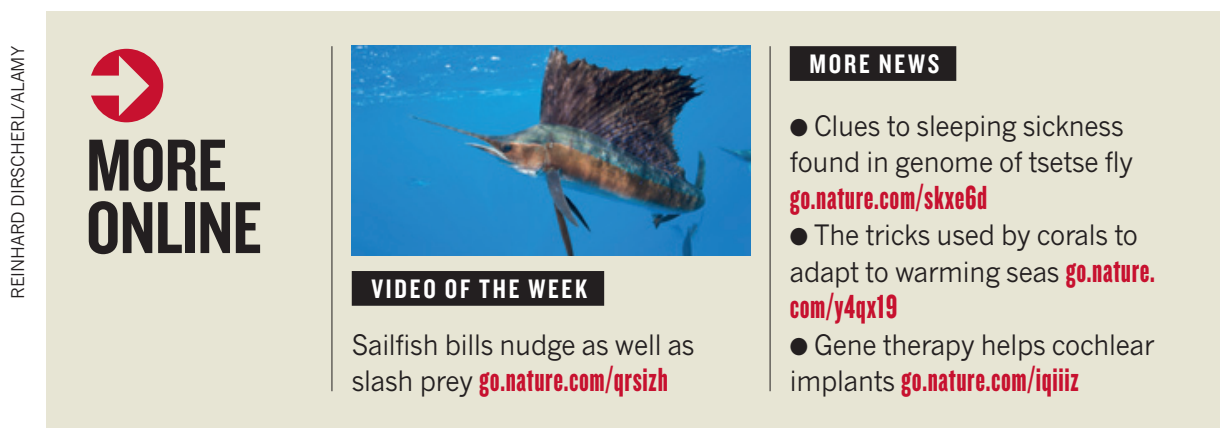

